\title{
ANALISIS KORELASI PENERIMAAN DENGAN HARGA DIRI ORANGTUA DAN STRES PENGASUHAN DALAM MERAWAT ANAK RETARDASI MENTAL
}

\author{
Yeni Fitria ${ }^{1}$, Sri Poeranto ${ }^{2}$, Lilik Supriati ${ }^{3}$ \\ ${ }^{1}$ Program Studi Magister Keperawatan Fakultas Kedokteran Universitas Brawijaya \\ 2,3 Fakultas Kedokteran Universitas Brawijaya \\ Jalan Veteran Malang 65145 \\ email: yeni.fitria040@gmail.com
}

\begin{abstract}
The condition of children with mental retardation become stressors for parents because of cognitive and adaptive function impairment causes need of special treatment in a variety of ways. It can have an impact on parental acceptance and parental self-esteem, which can lead parenting stress. This study aimed to analyze the correlation between parental acceptance, parent self-esteem and parenting stress in caring for mental retardation children. Design of this study was analytic correlation with cross sectional approach. The sampling technique used purposive sampling with 43 respondents. The research instrument used the Parental Acceptance Rejection Questionnaire/ (PARQ), Brief Self esteem Inventory/ (BSEI), and Parenting Stress Index Short Form/ (PSI-SF). Statistical analysis used Pearson correlation and path analysis. Data analysis showed that there is correlation between parental acceptance and parents self-esteem $(p=0.001 ; r=0.471 ; \rho=0.471)$. There is a relationship between the parental acceptance with parenting stress $(p=0.000 ; r=-0.554 ; \rho$ $=-0.383)$. There is a relationship between parents self-esteem with parenting stress $(p=0.000 ; r=-$ 0.544; $\rho=-0.364$ ). To minimize parenting stress in caring for mental retardation children, parents should enhance acceptance of child so they don't provide high demand to their child. In addition, parents need to have a positive assessment about themselves thus able to adapt to stressors experienced.
\end{abstract}

Keywords: parental acceptance, parent self esteem, parenting stress, mental retardation

Abstrak : Kondisi anak dengan retardasi mental menjadi stresor tersendiri bagi orangtua karena gangguan kognitif dan fungsi adaptifnya menyebabkan perlunya penanganan khusus dalam berbagai hal. Hal tersebut dapat berdampak pada penerimaan orangtua terhadap anak dan harga diri orangtua yang pada akhirnya dapat memicu timbulnya stres pengasuhan. Penelitian ini bertujuan untuk menganalisis korelasi antara penerimaan orangtua dengan harga diri orangtua dan stres pengasuhan dalam merawat anak retardasi mental. Rancangan penelitian ini adalah analitik korelasi dengan pendekatan cross sectional. Teknik sampling menggunakan purposive sampling dengan jumlah 43 responden. Instrumen penelitian yang digunakan yaitu Parental Acceptance Rejection Questionnaire/ (PARQ), Brief Self esteem Inventory/ (BSEI) dan Parenting Stres Index Short Form/ (PSI-SF). Analisis statistik menggunakan uji korelasi pearson dan analisis jalur (path analysis). Analisis data menunjukkan bahwa ada hubungan antara penerimaan dengan harga diri orangtua $(p=0,001 ; r=$ $0,471 ; \rho=0,471)$. Ada hubungan antara penerimaan orangtua dengan stres pengasuhan $(p=0,000 ; r=$ $-0,554 ; p=-0,383)$. Ada hubungan antara harga diri orangtua dengan stres pengasuhan $(p=0,000 ; r=-$ $0,544 ; \rho=-0,364)$. Untuk meminimalkan stres pengasuhan dalam merawat anak retardasi mental, sebaiknya orangtua lebih meningkatkan penerimaan terhadap anak sehingga tidak memberikan tuntutan yang melebihi kemampuan anak. Selain itu orangtua perlu memiliki penilaian positif terhadap diri sendiri sehingga lebih mampu beradaptasi dengan stresor yang dialami.

Kata Kunci: penerimaan orangtua, harga diri orangtua, stres pengasuhan, retardasi mental

\section{PENDAHULUAN}

Populasi anak retardasi mental menempati angka paling besar dibanding dengan jumlah anak dengan keterbatasan lainnya. Insiden tertinggi pada masa usia sekolah dengan usia puncak 10 - 14 tahun (Sadock \& Sadock, 2010). Sebuah metaanalisis yang dilakukan oleh Maulik et al., (2011) menyatakan bahwa prevalensi

secara global adalah 10,37/1000 populasi. Prevalensi retardasi mental di Indonesia saat ini diperkirakan 1-3\% dari penduduk Indonesia (sekitar 6,6 juta jiwa). Sekitar $85 \%$ dari seluruh kasus yang ada 
merupakan kasus ringan (Sadock \& Sadock, 2010). Meskipun sebagian besar retardasi mental merupakan kasus ringan, namun dampak yang dirasakan keluarga cukup besar, baik secara fisik maupun psikologis.

Kondisi anak dengan retardasi mental menjadi stresor tersendiri bagi orangtua karena gangguan kognitif dan fungsi adaptifnya menyebabkan perlunya penanganan khusus dalam berbagai hal, Kockar (2006) dan Ntswane \& Rhyn (2007) mengatakan bahwa ibu yang merawat anak dengan retardasi mental beresiko untuk mengalami stres. Penelitian yang dilakukan oleh Hidangmayun \& Khadi (2012) menunjukkan bahwa 73,4\% orangtua dengan anak disabilitas mental mengalami stres pengasuhan jika dibandingkan dengan orangtua anak normal.

Stres orangtua akan dirasakan lebih berat apabila orangtua memiliki harga diri rendah. Studi yang dilakukan oleh Maulina \& Sutatminingsih (2005) menunjukkan bahwa ada hubungan negatif antara harga diri dengan stres pada ibu yang memiliki anak retardasi mental. Individu dengan harga diri rendah cenderung lebih mudah mengalami stres karena memandang dirinya tidak berharga yang disertai perasaan inferior, takut atau mengalami kegagalan dalam mengadakan hubungan sosial, merasa tidak diperhatikan atau diasingkan, dan kurang mampu mengekspresikan diri (Lisnayanti, dkk., 2015).

$\begin{array}{ccc}\text { Salah } & \text { satu faktor yang } \\ \text { mempengaruhi } & \text { harga diri adalah }\end{array}$ penerimaan (Coopersmith, 1967; Stuart, 2013). Studi oleh Onder \& Gulay (2010) menunjukkan bahwa tingkat penolakan orangtua dengan anak retardasi mental lebih tinggi dibandingkan dengan orangtua anak normal. Penolakan orangtua terhadap anak akan mengakibatkan pengasuhan yang buruk (Bernard, 2014). Penerimaan orangtua yang rendah berhubungan dengan masalah eksternalisasi perilaku, seperti permusuhan dan agresi, harga diri rendah, kenakalan remaja, dan ketidakstabilan emosional. Penerimaan orangtua yang baik akan berpengaruh terhadap keterampilan sosial anak yang lebih positif (Sparks, 2010).
Berdasarkan hasil studi pendahuluan terhadap 10 responden yang dilakukan di Sekolah Dasar Luar Biasa (SDLB) Bhakti Luhur, diperolah data secara kualitatif yaitu semua responden mengalami perasaan sedih, syok, tidak percaya ketika mengetahui diagnosis anaknya. Sebanyak 8 responden merasa malu dan rendah diri dengan kondisi anaknya. Sebanyak 5 responden merasa diasingkan oleh lingkungannya. Sebanyak 7 responden mengalami stres selama merawa anak. Selain itu juga semua responden merasa khawatir dengan masa depan anak, mengingat anaknya tidak dapat mandiri secara penuh.

Penelitian ini bertujuan untuk menganalisis korelasi antara penerimaan orangtua dengan harga diri orangtua dan stres pengasuhan dalam merawat anak retardasi mental di SDLB Bhakti Luhur Kota Malang.

\section{METODE PENELITIAN}

Rancangan penelitian ini adalah analitik korelasional dengan pendekatan cross sectional. Teknik sampling menggunakan purposive sampling. Populasi dan sampel penelitian ini adalah orangtua yang memiliki anak retardasi mental yang bersekolah di SDLB Bhakti Luhur C dan C1 kelas 1 - 6. Jumlah sampel sebanyak 43 responden. Pengambilan data dilakukan tanggal 13 26 Mei 2016.

Instrumen penelitian yang digunakan yaitu Parental Acceptance Rejection Questionnaire/ PARQ, Brief Self esteem Inventory/ BSEI, dan Parenting Stres Index Short Form/ PSI-SF. Analisis statistik menggunakan uji korelasi pearson dan analisis jalur (path analysis).

Penelitian ini telah memperoleh kelayakan etik dari Poltekes Kemenkes Malang.

\section{HASIL PENELITIAN}

Tabel 1 Karakteristik Anak Berdasarkan Usia

\begin{tabular}{llcccc}
\hline No & Karakteristik & $\mathrm{n}$ & Mean & Med & SD \\
\hline 1 & Usia & 43 & 11,86 & 12 & 2, \\
& & & & & 765 \\
\hline & \multicolumn{4}{c}{ Sumber: data primer, 2016 }
\end{tabular}


Tabel 2 Karakteristik Anak Berdasarkan Tingkat Retardasi Mental

\begin{tabular}{cccc}
\hline No & \multicolumn{1}{c}{ Karakteristik } & f & $\%$ \\
\hline 1 & Tingkat Retardasi Mental & & \\
\hline a. RM Ringan & 9 & $21 \%$ \\
\hline b. RM Sedang & 22 & $51 \%$ \\
\hline c. RM Berat & 12 & $28 \%$ \\
\hline
\end{tabular}

Tabel 3 Karakteristik Orangtua Berdasarkan Usia

\begin{tabular}{cccccc}
\hline No & $\begin{array}{l}\text { Karak- } \\
\text { teristik }\end{array}$ & $\mathrm{n}$ & Mean & Med & SD \\
\hline 1 & Usia & 43 & 41,3 & 41 & 7,567 \\
\hline \multicolumn{5}{c}{} & \multicolumn{3}{c}{ Sumber: data primer, 2016 }
\end{tabular}

Tabel 4 Karakteristik Orangtua Berdasarkan Orangtua yang Dominan Merawat Anak, Pendidikan, Pekerjaan, Penghasilan Keluarga, Jumlah Anak, dan Status Perkawinan

\begin{tabular}{|c|c|c|c|}
\hline No & Karakteristik & $f$ & $\%$ \\
\hline 1 & $\begin{array}{l}\text { Orangtua yang Dominan } \\
\text { Merawat Anak }\end{array}$ & & \\
\hline & a. Ayah & 7 & $16 \%$ \\
\hline & b. $\quad \mathrm{lbu}$ & 36 & $84 \%$ \\
\hline 2 & Pendidikan & & \\
\hline & a. SD & 11 & $25 \%$ \\
\hline & b. SMP & 15 & $35 \%$ \\
\hline & c. SMU & 12 & $28 \%$ \\
\hline & d. Diploma/ Sarjana & 5 & $12 \%$ \\
\hline 3 & Pekerjaan & & \\
\hline & a. Bekerja & 15 & $35 \%$ \\
\hline & b. Tidak Bekerja & 28 & $65 \%$ \\
\hline 4 & Penghasilan Keluarga & & \\
\hline & a. $\quad<1,8$ juta & 33 & $77 \%$ \\
\hline & b. $>1,8$ juta & 10 & $23 \%$ \\
\hline 5 & Jumlah Anak & & \\
\hline & a. 1 orang & 10 & $23 \%$ \\
\hline & b. 2 orang & 22 & $51 \%$ \\
\hline & c. $=1>3$ orang & 11 & $26 \%$ \\
\hline 6 & Status Perkawinan & & \\
\hline & a. Kawin & 38 & $88 \%$ \\
\hline & $\begin{array}{l}\text { b. } \begin{array}{l}\text { Tidak kawin } \\
\text { (Janda/Duda) }\end{array} \\
\end{array}$ & 5 & $12 \%$ \\
\hline
\end{tabular}

3 , 4) didapatkan data rata-rata usia responden adalah 41,3 tahun. Sebagian besar responden yang dominan merawat anak adalah ibu yaitu 36 responden (84\%). Sebanyak 15 responden (35\%) memiliki tingkat pendidikan terakhir SMP dan hanya 5 responden $(12 \%)$ yang memiliki tingkat pendidikan terakhir Diploma/Sarjana. Lebih dari setengah responden, yaitu 28 responden (65\%) tidak bekerja. Sebagian besar responden, yaitu 33 responden
$(77 \%)$ memiliki penghasilan keluarga kurang dari 1,8 juta Rupiah/bulan (dibawah Upah Minimum Regional). Lebih dari setengah responden, yaitu 22 responden (51\%) memiliki 2 anak. Sebagian besar responden, yaitu 38 responden (88\%) responden berstatus kawin.

Sedangkan untuk karakteristik anak (tabel1, 2) diketahui bahwa rata - rata usia anak responden adalah 11,86 tahun dan lebih dari setengah responden, yaitu 22 responden (51\%) memiliki anak dengan tingkat retardasi mental sedang.

Untuk data khusus penelitian dijabarkan dalam tabel 5 .

Tabel 5 Deskripsi Variabel Penerimaan Orangtua, Harga Diri Orangtua, dan Stres Pengasuhan

\begin{tabular}{lrrrc}
\hline \multicolumn{1}{c}{ Variabel } & $\mathrm{n}$ & Mean & Median & $\mathrm{SD}$ \\
\hline $\begin{array}{l}\text { Penerimaan } \\
\text { orangtua }\end{array}$ & 43 & 70,26 & 70,00 & 8,021 \\
$\begin{array}{l}\text { Harga diri } \\
\text { orangtua }\end{array}$ & 43 & 53,53 & 52,00 & 6,819 \\
$\begin{array}{l}\text { Stres } \\
\text { pengasuhan }\end{array}$ & 43 & 46,60 & 45,00 & 7,835 \\
\hline
\end{tabular}

Sumber: data primer, 2016

Berdasarkan tabel 5 dapat dijelaskan bahwa pada variabel penerimaan orang tua didapatkan rata-rata skor sebesar 70,26 dengan nilai minimum 58 dan maksimum 86. Berdasarkan data tersebut dapat disimpulkan bahwa semua responden termasuk dalam kategori penerimaan, yang berarti bahwa semua orangtua dapat menerima anak dengan retardasi mental.

Pada variabel harga diri orang tua didapatkan rata-rata skor sebesar 53,53 dengan nilai minimum 40 dan maksimum 67. Berdasarkan data tersebut dapat disimpulkan bahwa rata-rata responden termasuk dalam kategori harga diri sedang.

Sedangkan pada variabel stres pengasuhan didapatkan rata-rata skor sebesar 46,60 dengan nilai minimum 34 dan maksimum 65. Berdasarkan data tersebut dapat disimpulkan bahwa rata-rata responden termasuk dalam kategori normal, yang berarti bahwa responden tidak mengalami stres pengasuhan dalam merawat anak retardasi mental.

Tabel 6 menggambarkan hasil analisis bivariat dengan menggunakan uji 
hipotesis korelasi Pearson karena skala data bersifat numerik.

Tabel 6 Hasil Analisis Bivariat

\begin{tabular}{lccc}
\hline \multicolumn{1}{c}{ Variabel } & $\mathbf{r}$ & $\mathbf{p}$ & Keterangan \\
\hline Penerimaan orangtua - harga diri orangtua & 0,471 & 0,001 & Signifikan \\
Harga diri orangtua - stres pengasuhan & $-0,544$ & 0,000 & Signifikan \\
Penerimaan orangtua - stres pengasuhan & $-0,554$ & 0,000 & Signifikan \\
\hline
\end{tabular}

Berdasarkan tabel 6 didapatkan bahwa ada hubungan antara penerimaan dengan harga diri orangtua $(r=0,471)$. Kekuatan hubungan cukup tinggi dengan arah positif. Ada hubungan antara harga diri orangtua dengan stres pengasuhan $(r=$ -0,544). Kekuatan hubungan cukup tinggi dengan arah negatif. Ada hubungan antara penerimaan orangtua dengan stres pengasuhan $(r=-0,554)$. Kekuatan hubungan cukup tinggi dengan arah negatif.

\section{Analisis Jalur (Path Analysis)}

Pada penelitan ini terdapat dua jalur hubungan antar variabel. Jalur pertama menggambarkan analisis jalur dari variabel penerimaan terhadap harga diri orangtua. Jalur kedua menggambarkan analisis jalur dari variabel penerimaan dan harga diri orangtua terhadap stres pengasuhan. Adapun bentuk persamaan struktur model penelitian sebagai berikut: Jalur 1: $Y_{\text {Harga diri orangtua }}=\rho_{\mathrm{yx}} \mathrm{X}+\rho_{\mathrm{y}} \varepsilon_{1}$ Jalur 2: $Z_{\text {Stres pengasuhan }}=\rho_{z x} X+\rho_{z y} Y+\rho_{z} \varepsilon_{2}$

Berikut ini tabel yang menunjukkan hasil analisis dari kedua jalur model penelitian.

Tabel 7 Hubungan Penerimaan (X) dengan Harga Diri Orangtua $(\mathrm{Y})$ dalam Merawat Anak Retardasi Mental

\begin{tabular}{cccccc}
\hline Variabel & R Square & Beta & Thitung & $\mathbf{T}_{\text {tabel }}$ & $\mathbf{p}$ Value \\
\hline Penerimaan $\rightarrow$ harga diri orangtua & 0,222 & 0,471 & 3,416 & 2,021 & 0,001 \\
\hline \multicolumn{4}{c}{ Sumber: data primer, 2016 }
\end{tabular}

Berdasarkan tabel 7 didapatkan bahwa $t$ hitung lebih besar dari $t$ tabel $(3,416>2,021)$ dan $p$ value lebih kecil dari $0,05(0,001<0,05)$, maka variabel penerimaan orangtua berhubungan langsung secara signifikan dengan harga diri orangtua dengan kontribusi sebesar
$0,471^{2}$ atau $22,2 \%$. Sisanya sebesar $77,8 \%$ dipengaruhi oleh faktor lain yang tidak diteliti. Adapun besar koefisien residu $\left(\rho_{y} \varepsilon_{1}\right)$ adalah $\sqrt{1-R^{2}}=\sqrt{1-0,222}=0,882$.

Tabel 8 Hubungan Penerimaan Orangtua (X) dengan Stres Pengasuhan (Z) melalui Pembentukan Harga Diri Orangtua $(\mathrm{Y})$ dalam Merawat Anak Retardasi Mental

\begin{tabular}{lcccc}
\hline \multicolumn{1}{c}{ Variabel } & R Square & F hitung & $F_{\text {tabel }}$ & $p$ Value \\
\hline $\begin{array}{l}\text { Penerimaan \& harga diri orangtua } \rightarrow \text { Stres } \\
\text { pengasuhan }\end{array}$ & 0,410 & 13,873 & 3,23 & 0,000 \\
\hline
\end{tabular}

Sumber: data primer, 2016

Berdasarkan tabel 8 untuk uji secara simultan (keseluruhan) didapatkan bahwa $F$ hitung lebih besar dari $F$ tabel $(13,873>3,23)$ dan $p$ value lebih kecil dari $0,05 \quad(0,000<0,05)$ maka dapat disimpulkan bahwa penerimaan orangtua dan harga diri orangtua berkontribusi secara simultan terhadap stres pengasuhan. Dengan demikian dapat dilakukan pengujian secara individual. 
Tabel 9 Hubungan Penerimaan Orangtua (X) dengan Stres Pengasuhan (Z) dalam Merawat Anak Retardasi Mental

\begin{tabular}{lccccc}
\hline \multicolumn{1}{c}{ Variabel } & R Square & Beta & $\mathbf{T}_{\text {hitung }}$ & $\mathbf{T}_{\text {tabel }}$ & $\mathbf{p}$ Value \\
\hline $\begin{array}{l}\text { Penerimaan } \rightarrow \text { Stres } \\
\text { Pengasuhan }\end{array}$ & 0,410 & - & $-2,779$ & 2,021 & 0,008 \\
\hline
\end{tabular}

Berdasarkan tabel 9 didapatkan bahwa t hitung lebih besar dari t tabel ($2,779>2,021)$ dan $p$ value lebih kecil dari $0,05(0,008<0,05)$ maka variabel penerimaan orangtua berhubungan langsung secara signifikan dengan stres pengasuhan dengan kontribusi sebesar $0,384^{2}$ atau $14,7 \%$.

Tabel 10 Hubungan Harga Diri Orangtua $(Y)$ dengan Stres Pengasuhan (Z) dalam Merawat Anak Retardasi Mental

\begin{tabular}{cccccc}
\hline Variabel & R Square & Beta & $\mathbf{T}_{\text {hitung }}$ & $\mathbf{T}_{\text {tabel }}$ & $\mathbf{p ~ V a l u e}$ \\
\hline Harga Diri Orangtua $\rightarrow$ & 0,410 & $-0,364$ & $-2,641$ & 2,021 & 0,012
\end{tabular}

Stres Pengasuhan

Sumber: data primer, 2016

Berdasarkan tabel 10 didapatkan bahwa $t$ hitung lebih besar dari t tabel ($2,641>2,021)$ dan $p$ value lebih kecil dari $0,05(0,012<0,05)$, maka variabel harga diri orangtua berhubungan langsung secara signifikan dengan stres pengasuhan dengan kontribusi sebesar $0,364^{2}$ atau $13,2 \%$.

Berdasarkan hasil analisis path
dapat digambarkan secara keseluruhan
hubungan kausal empiris antara
penerimaan orangtua, harga diri orangtua,
dan stres pengasuhan seperti pada
gambar 1.

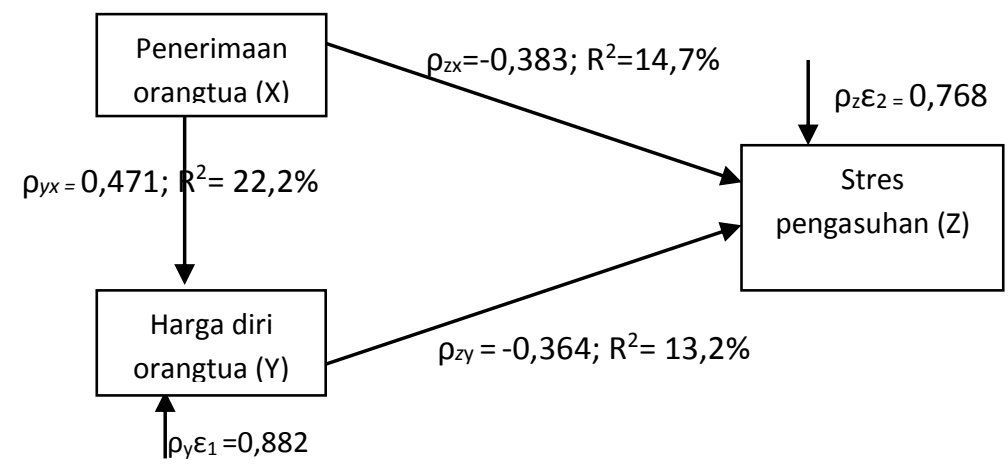

Gambar 1 Hubungan Kausal Empiris Variabel X,Y dengan Z

\section{PEMBAHASAN}

\section{Hubungan Langsung Penerimaan Orangtua terhadap Harga Diri Orangtua dalam Merawat Anak Retardasi Mental}

Berdasarkan hasil penelitian (tabel 3) rata-rata skor (mean) penerimaan orang tua didapatkan sebesar 70,26 dengan skor minimum 58 dan maksimum 86. Berdasarkan data tersebut dapat disimpulkan bahwa semua responden termasuk dalam kategori penerimaan, yang berarti bahwa semua orangtua dapat menerima anak dengan retardasi mental. Tidak ada orangtua yang termasuk dalam kategori penolakan, $\mathrm{Hal}$ ini diasumsikan karena orangtua merawat anak dalam waktu yang cukup lama, sehingga kemungkinan besar orangtua sudah mampu beradaptasi dengan stresor yang dialami selama merawat anak retardasi mental. Pernyataan tersebut didukung dengan data penelitian yang menunjukkan bahwa rata-rata usia anak yaitu 11,86 tahun.

Temuan penelitian ini didukung dengan pernyataan yang disampaikan oleh 
Kockar (2006) bahwa harga diri menjadi mediator antara penerimaan atau penolakan orang tua dengan timbulnya depresi. Hal ini menunjukkan bahwa penerimaan atau penolakan berhubungan dengan harga diri. Senada dengan hasil uji korelasi pearson (tabel 6) menunjukkan bahwa ada hubungan signifikan antara penerimaan dengan harga diri orangtua $(p=0,001 ; r=0,471)$. Kekuatan hubungan cukup tinggi dengan arah positif. Artinya semakin tinggi penerimaan maka semakin tinggi harga diri orangtua.

Berdasarkan hasil analisis jalur (path analysis) didapatkan bahwa penerimaan orangtua berhubungan langsung secara signifikan dengan harga diri orangtua dan memiliki kontribusi positif. Artinya tinggi rendahnya harga diri orangtua dalam merawat anak retardasi mental dapat dijelaskan oleh penerimaan orangtua dengan kontribusi sebesar $22,2 \%$. Hal ini sesuai dengan Stuart (2013) yang menyatakan bahwa salah satu faktor yang mempengaruhi harga diri adalah penerimaan, baik penerimaan terhadap diri sendiri maupun orang lain, dalam hal ini berkaitan dengan penerimaan terhadap anak yang mengalami retardasi mental. Orangtua yang memiliki penerimaan yang baik akan mampu mengenali kelebihan dan kekurangan anak. Dengan demikian akan memungkinkan bagi orangtua untuk menilai diri secara lebih realistis dan tidak memberikan tuntutan atau harapan yang melebihi kemampuan anak dengan retardasi mental.

\section{Hubungan Langsung Penerimaan Orangtua terhadap Stres Pengasuhan dalam Merawat Anak Retardasi Mental}

Hasil penelitian (tabel 3) menunjukkan bahwa rata-rata skor (mean) stres pengasuhan sebesar 46,60. Berdasarkan data tersebut dapat disimpulkan bahwa rata-rata responden termasuk dalam kategori normal, yang berarti bahwa rata-rata responden tidak mengalami stres pengasuhan dalam merawat anak retardasi mental. Hal ini dapat disebabkan karena adanya keterlibatan pasangan untuk berbagi peran dalam merawat anak sesuai dengan data penelitian yang menunjukkan bahwa $88 \%$ orangtua berstatus kawin. Pernyataan ini sesuai dengan Lestari (2012) yang menyatakan bahwa struktur keluarga dapat mempengaruhi stres pengasuhan.

Berdasarkan hasil uji korelasi Pearson (tabel 6) menunjukkan bahwa ada hubungan yang signifikan antara penerimaan dengan stres pengasuhan $(p=$ $0,000 ; \quad r=-0,554)$. Kekuatan hubungan cukup tinggi dengan arah negatif. Artinya semakin tinggi penerimaan orangtua maka semakin rendah stres pengasuhan dalam merawat anak retardasi mental.

Berdasarkan hasil analisis jalur (path analysis) didapatkan bahwa penerimaan orangtua berhubungan langsung secara signifikan dengan stres pengasuhan dan memiliki kontribusi negatif. Artinya tinggi rendahnya stres pengasuhan dalam merawat anak retardasi mental dapat dijelaskan oleh penerimaan orangtua dengan kontribusi $14,7 \%$.

Penerimaan orangtua terjadi ketika orangtua menerima anak terlepas dari penampilan, kemampuan, atau perilaku anak, sensitif terhadap kebutuhan, keinginan dan kepentingan anak (Bernard, 2014). Disabilitas perkembangan pada anak akan mempengaruhi tingkat penerimaan orang tua (Aydin \& Yamac, 2014). Kemampuan adaptasi, perilaku yang sulit, permintaan yang berlebihan, dan ketidakmampuan penyesuaian diri anak retardasi mental dilihat sebagai penyebab utama dari stres pengasuhan (Karasavvidis, et al., 2011).

$$
\text { Orangtua yang memiliki }
$$

penerimaan yang baik akan dapat menciptakan lingkungan yang positif dalam keluarga, dan mampu menerima kondisi anak dengan kekurangan atau keterbatasan yang dimiliki. Dalam hal ini orangtua menyadari tuntutan yang diberikan kepada anak yang akan disesuaikan dengan kemampuan anak. Dengan memiliki harapan yang realistis terhadap anak akan membuat orangtua lebih mampu beradaptasi selama merawat anak dengan retardasi mental. Temuan penelitian ini sesuai dengan penelitian Fernandes (2015) yang menunjukkan bahwa penerimaan orangtua berkorelasi negatif dengan stres pengasuhan. 


\section{Hubungan Langsung Harga Diri Orangtua terhadap Stres Pengasuhan dalam Merawat Anak Retardasi Mental}

Berdasarkan hasil uji korelasi pearson (tabel 6) menunjukkan bahwa ada hubungan yang signifikan antara harga diri orangtua dengan stres pengasuhan $(p=0,000, r=-0,544)$. Kekuatan hubungan cukup tinggi dengan arah negatif. Artinya semakin tinggi harga diri maka semakin rendah stres pengasuhan dalam merawat anak retardasi mental.

Berdasarkan hasil analisis jalur (path analysis) didapatkan bahwa harga diri orangtua berhubungan langsung secara signifikan dengan stres pengasuhan dan memiliki kontribusi negatif. Artinya tinggi rendahnya stres pengasuhan dalam merawat anak retardasi mental dapat dijelaskan oleh harga diri orangtua dengan kontribusi 13,2\%.

Temuan ini sesuai dengan studi oleh Maulina \& Sutatminingsih (2005) yang menyatakan bahwa orangtua yang memiliki anak retardasi mental akan merasakan harga diri rendah, sesuai dengan hasil penelitian yang menunjukkan bahwa $57 \%$ ibu dari anak retardasi mental memiliki harga diri negatif. Hal ini terjadi karena orangtua memiliki anak yang tidak sesuai dengan harapan. Harga diri rendah dapat dilihat dari adanya perasaan malu dengan keberadaan anak yang cacat.

Hal ini senada dengan pendapat Lisnayanti dkk. (2015) yang menyatakan bahwa individu dengan harga diri rendah cenderung lebih mudah mengalami stres karena memandang dirinya tidak berharga yang disertai perasaan inferior, takut atau mengalami kegagalan dalam mengadakan hubungan sosial, merasa tidak diperhatikan atau diasingkan, dan kurang mampu mengekspresikan diri.

Salah satu indikator stress pengasuhan dari faktor orangtua yaitu Feelings of competence yaitu orangtua diliputi oleh tuntutan peran dan perasaan kurang terhadap kemampuan dalam merawat anak. Hal ini dihubungkan dengan kurangnya pengetahuan orangtua dalam hal perkembangan anak dan ketrampilan menejemen anak yang sesuai. Hal ini sesuai dengan hasil penelitian ini yang menunjukkan bahwa $35 \%$ orangtua memiliki tingkat pendidikan terakhir SMP dan hanya $5 \%$ yang berada pada tingkat diploma/sarana. Semakin tinggi pendidikan individu diharapkan semakin tinggi pengetahuan yang dimiliki, terutama berkaitan dengan perawatan anak retardasi mental. Sehingga dengan memiliki pengetahuan yang cukup orangtua akan merasa berkompeten merawat anak dengan kebutuhan khusus.

Hasil penelitian ini memiliki implikasi terhadap praktik keperawatan yaitu perawat dapat berperan aktif dengan memberikan logoterapi bagi orangtua untuk memodifikasi pikiran negatif terhadap anak dan terhadap diri sendiri dalam mempersepsikan situasi maupun stresor yang dihadapi dalam merawat anak retardasi mental. Melalui logoterapi diharapkan orangtua dapat lebih memahami makna pengalaman dalam merawat anak retardasi mental.

\section{KESIMPULAN}

Penerimaan orangtua berhubungan secara langsung terhadap harga diri orangtua dengan kontribusi 22,2\%; Penerimaan orangtua berhubungan secara langsung terhadap stres pengasuhan dengan kontribusi negatif sebesar $14,7 \%$; Harga diri orangtua berhubungan secara langsung terhadap stres pengasuhan dengan kontribusi negatif sebesar $13,2 \%$

\section{SARAN}

Untuk meminimalkan stres pengasuhan dalam merawat anak retardasi mental, sebaiknya orangtua lebih meningkatkan penerimaan terhadap anak sehingga tidak memberikan tuntutan yang melebihi kemampuan anak. Selain itu juga perlu memiliki penilaian positif terhadap diri sendiri sehingga lebih mampu beradaptasi dengan stresor yang dialami.

Untuk penelitian selanjutnya disarankan menggunakan pendekatan penelitian yang berbeda dengan memperluas cakupan responden agar hasil penelitian dapat digeneralisasikan. 


\section{DAFTAR PUSTAKA}

Abidin, R. R. (1992). Parenting Stress Index, Third Edition: Professional Manual. Odessa, FL: Psychological Assessment Resources, Inc.

Ahern, Lisa S. (2004). Psychometric properties of the parenting stress index - short form. Diakses dari http//respiratory.lib.ncsu.edu/ir/handle/ 1840.16/2765.

Bernard, Michael E. (2014). The Strength of Self-Acceptance: Theory, Practice and Research. Melbourne: Springer science \& bussiness media

.Berry, JD, \& Jones, W,H, (1995) The Parental Stress Scale : initial psychometric evidence. Journal of Social and Personal Relationships. 12, $463-472$.

Coopersmith, S. (1967). The Antecedents of Self-esteem. San fransisco: W. H Freeman \& co.

Deater, Deckard K. (2004). Parenting stress. CT: Yale university press.

Elford, Lauren M., (2015) "Mothers' Lived Experience of Parenting an Infant/Young Child with Special Needs in a Rural Context". University of Western Ontario - Electronic Thesis and Dissertation Repository. Paper 2688.

Ferrell, Lisa G. (2003). A Comparison of an Intensive 4-Week Format of The Landreth 10-Week Filial Therapy Training Model With The Traditional Landreth 10-Week Model of Filial Therapy. Disertasi. University of North Texas.

Glenn. (2014). Using Online Health Communication to Manage Chronic Sorrow: Mothers of Children with Rare Disease Speak. Disertasi. George Mason University.

Green, Sara Eleanor. (2004). The impact of stigma on maternal attitudes toward placement of children with disabilities in residential care facilities. Social Science \& Medicine 59: 799-812.

Green, Sara Eleanor. (2007). "We're tired, not sad": Benefits and burdens of mothering a child with a disability. Social Science \& Medicine 64: 150163.

Hidangmayun \& Khadi (2012). Parenting stress of normal and mentally challenged children. Karnataka J. Agric. Sci.,25 (2) : (256-259).

Hurlock, E. B. (2007). Psikologi Perkembangan : suatu Pendekatan Sepanjang Rentang kehidupan (terjemahan: Istiwidayati). Jakarta: Erlangga.

Jamison, et al. (2006). Disease control priorities in developing countries, Washington DC: the international bank for Reconstruction and Development/ The World Bank.

Johnston, Cindy. (2003). Factors associated with parenting stress in mother of children with fragile $X$ syndrome. Journal of Developmental and Behavioral Pediatrics. Vol 24 (4): 267- 275.

Karasavvidis, et al., (2011). Review paper: Mental retardation and parenting stress. International Journal of caring Sciences.

Khaleque, A. \& Rohner, R. P. (2002). Reliability of measures assessing the relation between perceived parental acceptance-rejection and psychological adjustment: A metaanalysis of cross-cultural and intracultural studies. Journal of CrossCultural Psychology: 33, 86-98.

Lestari,Sri. (2012). Psikologi Keluarga: Penanaman Nilai dan Penanganan Konflik Dalam Keluarga. Jakarta : Kencana Prenada Media Group.

Lisnayanti, dkk. (2015). Hubungan tingkat harga diri (self-esteem) dengan tingkat ansietas orang tua dalam merawat anak tunagrahita Di SDLB C Negeri Denpasar. Coping Ners Journal. 3(2): $15-21$.

Maslim, Rusdi. 2002. Diagnosis Gangguan Jiwa: Rujukan Ringkas PPDGJ-III. Jakarta: bagian ilmu Kedokteran Jiwa FK Unika Atmajaya.

Maulik, et al. (2011). Research in Developmental Disabilities. 32: 419 436.

Maulina \& Sutatminingsih (2005). Stres ditinjau dari harga diri pada ibu yang memiliki anak penyandang retarasi mental. Psikologia. 1(1): 11-18.

McKeever, Patricia and Miller. (2004). Mothering children who have disabilities: a Bourdieusian 
interpretation of maternal practices. Social Science \& Medicine 59: 11771191.

McKenzie, et al. (2012). The Evaluation of a screening tool for children with an intellectual disability. Research in Developmental Disabilities. 33: 1068 1075.

McNally, Anna \& Mannan, Hasheem. (2013). Perception of caring for children with disabilities: experiences from Moshi, Tanznia. African Journal of Disability 2(1), Art. \#21, 10 pages.

Mirza, et.al. (2009). Community management of intellectual disabilities in Pakistan: a mixed method study. Journal of Intellectual Disability Research. 53 (6): 559 -570.

Nasir dan Muhith. (2011). Dasar-dasar Keperawatan Jiwa: Pengantar dan Teori. Jakarta: Salemba Medika.

National Safety Council. (2004). Manajemen Stres. Jakarta: EGC

.Ntswane, AM \& Rhyn, L.van. (2007). The life-world of mothers who care for mentally retarded children: the Katutura township experience. Curationis. 30 (1): $85-96$.

Rohner, R.P., Khaleque A., Cournoyer, David E. (2007). Introduction to parental acceptance - rejection theory, methods, evidence and implication. Human Development and Family Studies of University of Connecticut. Diunduh dari www.cspar.uconn.edu/intro_partheory. html.
Rohner. (2012). Introduction to parental acceptance - rejection theory, methods, evidence and implication. Human Development and Family Studies of University of Connecticut.

Sadock, Benjamin J \& Sadock, Virginia A. (2010). Buku Ajar Psikiatri Klinis. Jakarta: EGC.

Santrock, John W. (2005). Children Development. New York: Mc. Graw Hill.

Somantri, Sutjihati. 2007. Psikologi Anak Luar Biasa. Bandung: PT Refika Aditama. 103.

Stuart, G. W \& Lararia, M. T. (2005). Principles and Practice of Psychiatric Nursing. (8th). St. Louis: Mosby.

Stuart, G. W. (2013). Principles and Practice of Psychiatric Nursing. (10th). St. Louis: Mosby.

Sularyo, Titi S. \& Kadim, M.(2000). Retardasi Mental. Sari Pediatri. 2(3): $170-177$.

Tavakolizadeh, J. et al. (2012). The effect of rational-emotional training on mothers' mental health condition of children with mental retardation. Procedia - Social and Behavioral Sciences 69: $649-658$.

Townsend, M. C. (2013). Essentials of Psychiatric Mental Health Nursing. 6th Edition. Philadelphia: F. A. Davis Company.

Walker, Alexis Philbin. (2000). Parenting Stress: A Comparison of Mothers and Fathers of Disabled And Non-Disabled Children. Disertasi. University of North Texas. 